\title{
Machine Learning Methods for Managing Parkinson's Disease
}

\author{
Kumar R., E. Laxmi Lydia, K. Shankar, Phong Thanh Nguyen, Satria Abadi
}

\begin{abstract}
This is a fact that more than one and half million patients are suffering from Parkinson's disease in the big countries like China, United States, Russia and worldwide is around 6 millions. Even after of many worldwide experiments and research the Parkinson's disease is an major challenge for biomedical research, scientists and doctors. The problem of this research is that the symptoms of the disease can be investigated in the early and late early age. So that it becomes very difficult to know accurately about this disease. In order to do this research initially some random numbers of features are selected for the research. These features are extracted by many neural network algorithms with minimum redundancy and the maximum similar feature selection. The accuracy of the algorithms results is also a very big concern. It is assumed that the selection algorithms must provide overall 92.3\%, precision $21.2 \%$ and MC coefficient values of $0.75 \&$ ROC value $0.97 \%$. If such results are achieved then that means it is better than previous research and the work is in improvement process. There are many machine learning algorithms used in different countries based on the research approaches like SVM, DT, PPDM, Artificial intelligence etc. Often the people are aware with the symptoms of this disease so if the proper treatment is given at proper time then the patients may get proper treatment on time and this leads to boost the recovery time. There are many machine learning algorithms and models are under development process which may help to predict the disease in early stage. In this research an automated diagnostic system is introduced. The Multilayer perception, BayesNet and other algorithms are used. This research also provides the observation that such models and methods can help to recover a patient in minimum time because of the early stage prediction of disease.
\end{abstract}

Keywords : Parkinson's Prediction, Machine Learning Algorithms, Artificial Intelligence System, BayesNet, Data Mining Algorithms.

\section{INTRODUCTION}

Indeed, even after of numerous overall tests and research the Parkinson's infection is a noteworthy test for biomedical research, researchers and specialists. The issue of this

Revised Manuscript Received on July 22, 2019

* Correspondence Author

Kumar R., Department of Computer Science, Kristu Jayanti College, Bangalore-560043, India.

E. Laxmi Lydia, Professor, Vignan's Institute of Information Technology(A),Department of Computer Science and Engineering, Visakhapatnam, Andhra Pradesh, India.

K. Shankar*, Department of Computer Applications, Alagappa University, Karaikudi, India. E-mail: shankarcrypto@gmail.com

Phong Thanh Nguyen*, Department of Project Management, Ho Chi Minh City Open University, Vietnam. E-mail: phong.nt@ou.edu.vn

Satria Abadi, Department of Information Systems, STMIK Pringsewu, Lampung, Indonesia.

exploration is that the manifestations of the infection can be examined in the early and late early age. So it turns out to be exceptionally hard to think precisely about this malady. So as to do this examination at first some arbitrary quantities of highlights are chosen for the exploration. These highlights are separated by numerous neural system calculations with least repetition and the most extreme comparative component choice. The exactness of the calculations results is likewise a major concern. It is expected that the determination calculations must give generally $92.3 \%$, accuracy $21.2 \%$ and MC coefficient estimations of 0.75 and ROC esteem $0.97 \%$. In the event that such outcomes are accomplished, at that point that implies it is superior to anything past research and the work is in progress process. The prediction analysis strategy for Parkinson's disease is shown in the figure below:
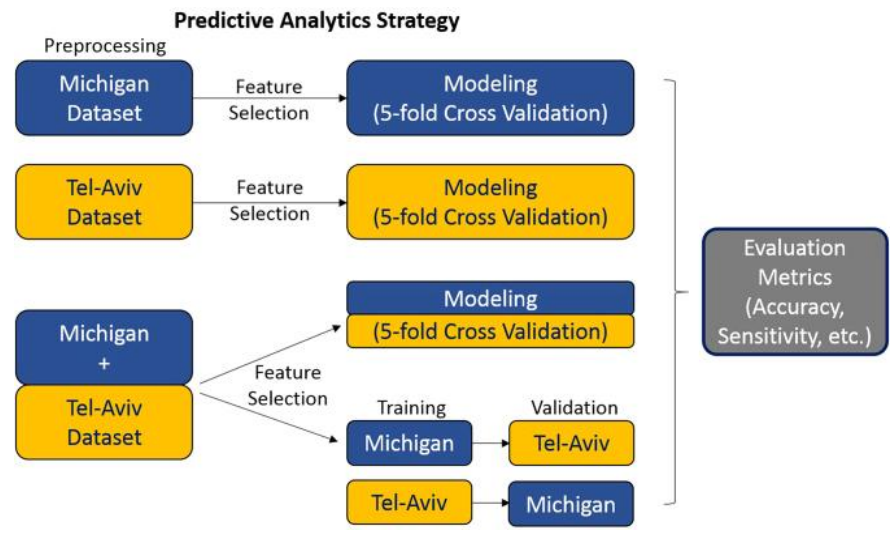

Figure 1. Parkinson's Disease Predictive Analysis Strategy Flow Diagram

In this examination numerous procedures, strategies and calculations are read and actualized for the datasets assembled from different assets. The underlying attempted to show signs of improvement results. At that point the examination center around high precision with boosting the time taken in analyze the illness by existing work. The $\mathrm{N}$ number of information is taken and the component extraction calculations are connected on this information. The side effects delivered with this removed information are contrasted with the current calculations assessments results. It is seen that the 20 highlights are chosen with MRMR include determination calculations and in general precision is superior to the past work.

The Necessary factors of this research is given below:

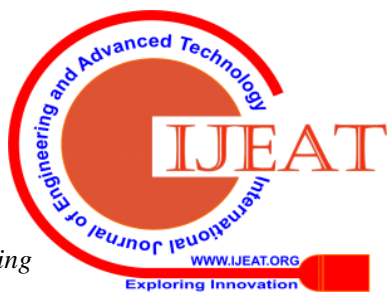


Preprocessing

- Patient Datasets

- Tel-Aviv Datasets

- Hybrid Sets

Algorithms

- Feature Selection

\section{Post Processing}

- Modeling of Results

- Software Training

- Results Validation

- Generate Result Data and Evaluation Metrics

There are many AI calculations utilized in various nations dependent on the exploration methodologies like SVM, DT, PPDM, Artificial insight and so on. This is a reality that mutiple and half million patients are experiencing Parkinson's sickness in the enormous nations like China, United States, Russia and worldwide is around 6 millions. Regularly the individuals know with the manifestations of this ailment so in the event that the correct treatment is given at legitimate time, at that point the patients may get appropriate treatment on schedule and this prompts help the recuperation time.

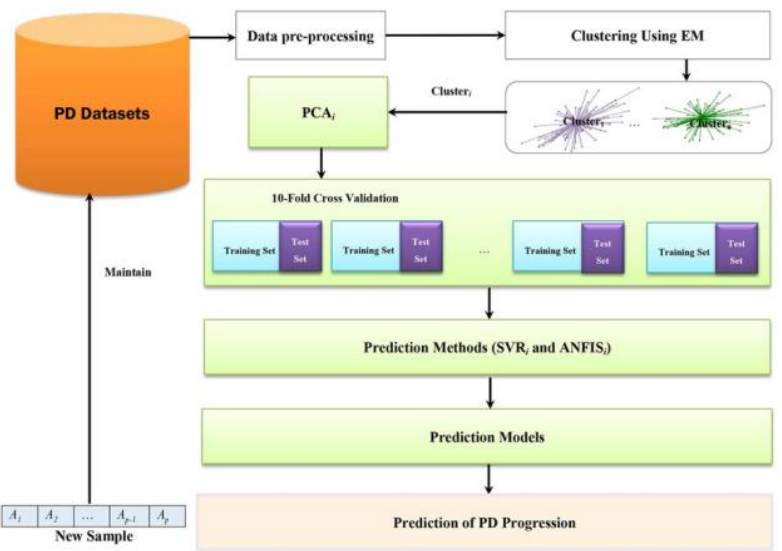

Figure 2. Predictive Analysis and Results Improvement process

There are many AI calculations and models are being worked on procedure which may foresee the illness in beginning time. In this examination a mechanized demonstrative framework is presented. The Multilayer observation, BayesNet and different calculations are utilized. This examination likewise gives the perception that such models and techniques can recoup a patient in least time in view of the beginning time expectation of infection.

\section{METHODS AND METHODOLOGIES}

The patient datasets for this research are collected from the independent researchers, clinical data and hospitals. The algorithms methods for feature extractions of voice disorder.

\section{Machine Learning Supporting Algorithms}

Randomized Algorithms, Privacy preserving datamining algorithms are used for ensemble of the randomized trees. Such trees are generated by synchronized sample data. After every measurement the highest data is selected for gaining information.

\section{Random Forests}

The final decision is based on the basis of accuracy of algorithm results. Such comparison are performed by decision tree based algorithms such as CART.

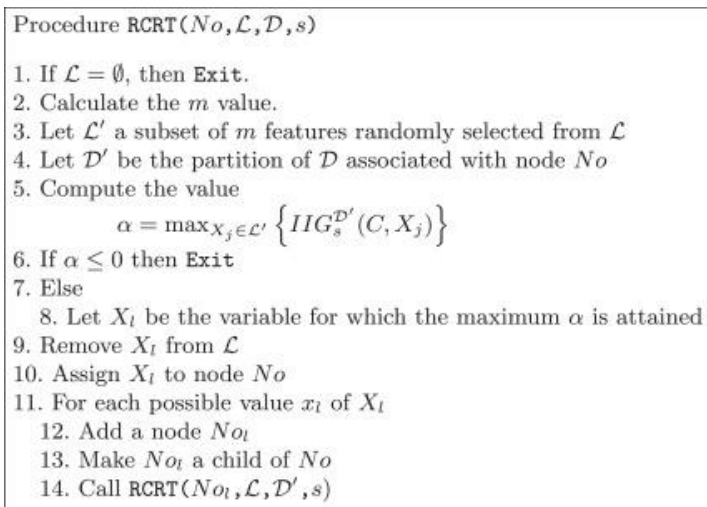

Figure 3. Random Forests Algorithm

\section{RESULTS AND ANALYSIS}

In this research many techniques, methods and algorithms are studied and implemented for the datasets gathered from various resources. The initial tried to get the better results. Then the research focus on high accuracy with boosting the time taken in diagnose the disease by existing work. The $\mathrm{N}$ number of data is taken and the feature extraction algorithms are applied on this data. The symptoms produced with this extracted data are compared to the existing algorithms evaluations results. It is observed that the 20 features are selected with MRMR feature selection algorithms and overall accuracy is better than the previous work. The result is shown in the table below: 
TABLE 1: Result ANALYSIS AND PREDICTIVE RESUlts

\begin{tabular}{|c|l|c|c|c|c|c|c|c|c|}
\hline \multirow{4}{*}{ S V M } & Parkinson & 95.2 & 80.9 & 0.36 & 0.63 & 97.3 & 83.1 & 0.49 & 0.68 \\
\cline { 2 - 9 } & no Parkinson & 31.3 & 68.2 & 0.36 & 0.63 & 39.6 & 82.6 & 0.49 & 0.68 \\
\cline { 2 - 9 } & Overall & 79.5 & 77.8 & 0.36 & 0.63 & 83.1 & 83 & 0.49 & 0.68 \\
\hline \multirow{4}{*}{ MLP } & Parkinson & 93.9 & 80.2 & 0.31 & 0.78 & 95.9 & 86.5 & 0.58 & 0.89 \\
\cline { 2 - 9 } & no Parkinson & 29.2 & 60.9 & 0.31 & 0.78 & 54.2 & 81.3 & 0.58 & 0.89 \\
\cline { 2 - 9 } & Overall & 77.9 & 75.5 & 0.31 & 0.78 & 85.6 & 85.2 & 0.58 & 0.89 \\
\hline \multirow{3}{*}{ Decision Tree } & Parkinson & 88.4 & 87.2 & 0.50 & 0.72 & 94.6 & 87.4 & 0.59 & 0.80 \\
\cline { 2 - 9 } & no Parkinson & 60.4 & 63 & 0.50 & 0.72 & 58.3 & 77.8 & 0.59 & 0.80 \\
\cline { 2 - 9 } & Overall & 81.5 & 81.3 & 0.50 & 0.72 & 85.6 & 85 & 0.59 & 0.80 \\
\hline \multirow{3}{*}{ Random Forest } & Parkinson & 94.6 & 91.4 & $\mathbf{0 . 7 0}$ & $\mathbf{0 . 9 2}$ & $\mathbf{9 5 . 9}$ & $\mathbf{9 1 . 6}$ & $\mathbf{0 . 7 3}$ & $\mathbf{0 . 9 0}$ \\
\cline { 2 - 9 } & no Parkinson & $\mathbf{7 2 . 9}$ & $\mathbf{8 1 . 4}$ & $\mathbf{0 . 7 0}$ & $\mathbf{0 . 9 2}$ & $\mathbf{7 2 . 9}$ & $\mathbf{8 5 . 4}$ & $\mathbf{0 . 7 3}$ & $\mathbf{0 . 9 0}$ \\
\cline { 2 - 9 } & Overall & $\mathbf{8 9 . 2}$ & 89 & $\mathbf{0 . 7 0}$ & $\mathbf{0 . 9 2}$ & $\mathbf{9 0 . 3}$ & $\mathbf{9 0}$ & $\mathbf{0 . 7 3}$ & $\mathbf{0 . 9 0}$ \\
\hline
\end{tabular}

Table 2. Classifier and Feature Selection Algorithms Predictive Results

\begin{tabular}{|c|c|c|c|c|c|c|c|c|c|}
\hline \multirow[t]{2}{*}{ Classifiers } & \multicolumn{5}{|c|}{10 Features Selected by MIRMIR } & \multicolumn{4}{|c|}{15 Features Selected by MIRIR } \\
\hline & Class & $\begin{array}{c}\text { Accurac } \\
y\end{array}$ & $\begin{array}{c}\text { Precisio } \\
\text { n }\end{array}$ & $\begin{array}{c}\mathrm{MC} \\
\mathrm{C}\end{array}$ & $\begin{array}{l}\text { RO } \\
\text { C }\end{array}$ & Accuracy & Precision & $\begin{array}{c}\mathrm{MC} \\
\mathrm{C}\end{array}$ & $\begin{array}{c}\text { RO } \\
\text { C }\end{array}$ \\
\hline \multirow{3}{*}{ Bagging } & Parkinson & 95.2 & 89.2 & 0.65 & 0.90 & 95.2 & 89.2 & 0.65 & 0.90 \\
\hline & noParkinson & 64.6 & 81.6 & 0.65 & 0.90 & 64.6 & 81.6 & 0.65 & 0.90 \\
\hline & Overall & 87.7 & 87.3 & 0.65 & 0.90 & 87.7 & 87.3 & 0.65 & 0.90 \\
\hline \multirow{3}{*}{ Boosting } & Parkinson & 93.2 & 91.9 & 0.69 & 0.92 & 95.2 & 89.2 & 0.65 & 0.90 \\
\hline & no Parkinson & 75 & 78.3 & 0.69 & 0.92 & 64.6 & 81.6 & 0.65 & 0.90 \\
\hline & Overall & 88.7 & 88.6 & 0.69 & 0.92 & 87.7 & 87.3 & 0.65 & 0.90 \\
\hline \multirow{3}{*}{ Random Forest } & Parkinson & 95.9 & 91.6 & 0.73 & 0.93 & 95.9 & 90.4 & 0.70 & 0.92 \\
\hline & noParkinson & 72.9 & 85.4 & 0.73 & 0.93 & 68.8 & 84.6 & 0.70 & 0.92 \\
\hline & Overall & 90.3 & 90 & 0.73 & 0.93 & 89.2 & 89 & 0.70 & 0.92 \\
\hline \multirow{3}{*}{ Rotation Forest } & Parkinson & 95.2 & 90.9 & 0.70 & 0.94 & 95.2 & 89.7 & 0.67 & 0.92 \\
\hline & no Parkinson & 70.8 & 82.9 & 0.70 & 0.94 & 66.7 & 82.1 & 0.67 & 0.92 \\
\hline & Overall & 89.2 & 88.9 & 0.70 & 0.94 & 88.2 & 87.9 & 0.67 & 0.92 \\
\hline \multirow{3}{*}{$\begin{array}{l}\text { Random } \\
\text { Subspace }\end{array}$} & Parkinson & 97.3 & 85.1 & 0.56 & 0.88 & 96.6 & 86.1 & 0.58 & 0.89 \\
\hline & noParkinson & 47.9 & 85.2 & 0.56 & 0.88 & 52.1 & 83.3 & 0.58 & 0.89 \\
\hline & Overall & 85.1 & 85.1 & 0.56 & 0.88 & 85.6 & 85.4 & 0.58 & 0.89 \\
\hline \multirow{3}{*}{ SVM } & Parkinson & 97.3 & 82.7 & 0.47 & 0.67 & 98.6 & 78.8 & 0.33 & 0.59 \\
\hline & no Parkinson & 37.5 & 81.8 & 0.47 & 0.67 & 18.8 & 81.8 & 0.33 & 0.59 \\
\hline & Overall & 82.6 & 82.5 & 0.47 & 0.67 & 79 & 79.5 & 0.33 & 0.59 \\
\hline \multirow{3}{*}{ MLP } & Parkinson & 96.6 & 88.2 & 0.65 & 0.89 & 93.2 & 89 & 0.61 & 0.92 \\
\hline & no Parkinson & 60.4 & 85.3 & 0.65 & 0.89 & 64.6 & 75.6 & 0.61 & 0.92 \\
\hline & Overall & 87.7 & 87.5 & 0.65 & 0.89 & 86.2 & 85.7 & 0.61 & 0.92 \\
\hline \multirow{3}{*}{ Decision Tree } & Parkinson & 94.6 & 87.4 & 0.59 & 0.78 & 93.2 & 91.3 & 0.68 & 0.86 \\
\hline & no Parkinson & 58.3 & 77.8 & 0.59 & 0.78 & 72.9 & 77.8 & 0.68 & 0.86 \\
\hline & Overall & 85.6 & 85 & 0.59 & 0.78 & 88.2 & 88 & 0.68 & 0.86 \\
\hline
\end{tabular}

\section{CONCLUSION}

For sure, even after of various in general tests and research the Parkinson's disease is an essential test for biomedical research, scientists and pros. The issue of this investigation is that the signs of the disease can be inspected in the early and late early age. So it ends up being incredibly difficult to contemplate this disease. In order to do this assessment from the start some self-assertive amounts of features are picked for the investigation. These features are isolated by various neural framework estimations with least redundancy and the most outrageous near part decision. The precision of the counts results is in like manner a noteworthy concern.

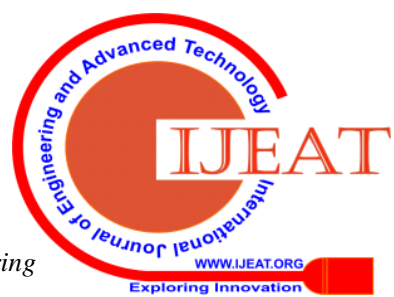


It is normal that the assurance counts must give commonly $92.3 \%$, precision $21.2 \%$ and MC coefficient estimations of 0.75 and ROC regard $0.97 \%$.

If such results are practiced, by then that suggests it is better than anything past research and the work is in advancement process. There are numerous AI figurings used in different countries reliant on the investigation systems like SVM, DT, PPDM, Artificial understanding, etc. This is a reality that mutiple and half million patients are encountering Parkinson's disorder in the gigantic countries like China, United States, Russia and worldwide is around 6 millions. Routinely the people know with the indications of this sickness so if the right treatment is given at authentic time, by then the patients may get proper treatment on timetable and this prompts help the recovery time. There are numerous AI estimations and models are being taken a shot at technique which may anticipate the ailment in starting time. In this assessment a motorized decisive structure is exhibited. The Multilayer perception, BayesNet and various computations are used.

This assessment in like manner gives the observation that such models and methods can recover a patient in least time in perspective on the starting time desire for disease.

\section{FUTURE WORK}

There is always possibility that using hybrid algorithms and more data sets may help to improve the prediction accuracy, the occupied time and boosting the early stage prediction. The program may include deep learning strategy which may lead the process of fully dependency on computer system analysis.

\section{ACKNOWLEDGMENT}

This article has been written with financial support of RUSA-Phase 2.0 grant sanctioned vide Letter No. F. 24-51/2014-U, Policy (TNMulti-Gen), Dept. of Edn. Govt. of India, Dt. 09.10 .2018 .

\section{REFERENCES}

1. Sethi, K. Leodopa unresponsie symptoms in Parkinson disease. Moement Disorders23 (2008). [PubMed]

2. Perez-Lloret $\mathrm{S}$, et al. Prealence, determinants, and effect on quality of life of freezing of gait in Parkinson disease. JAMA neurology. 2014;71:884-890. doi: 10.1001/jamaneurol.2014.753. [PubMed] [CrossRef] [Google Scholar]

3. Okuma Y, de Lima ALS, Fukae J, Bloem BR, Snijders AH. A prospectie study of falls in relation to freezing of gait and response fluctuations in Parkinson's disease. Parkinsonism \& related disorders. 2018;46:30-35. doi: 10.1016/j.parkreldis.2017.10.013. [PubMed] [CrossRef] [Google Scholar]

4. Bloem BR, Grimbergen YA, Cramer M, Willemsen M, Zwinderman AH. Prospectie assessment of falls in Parkinson's disease. Journal of neurology. 2001;248:950-958. doi: 10.1007/s004150170047. [PubMed] [CrossRef] [Google Scholar]

5. Hughes AJ, Daniel SE, Blankson S, Lees AJ. A clinicopathologic study of 100 cases of Parkinson's disease. Arch Neurol. 1993;50:140-148. doi: 10.1001/archneur.1993.00540020018011. [PubMed] [CrossRef] [Google Scholar]

6. u TC, Nutt JG, Holford NH. Progression of motor and nonmotor features of Parkinson's disease and their response to treatment. $\mathrm{Br} \mathrm{J}$ Clin Pharmacol. 2012;74:267-283. doi: 10.1111/j.1365-2125.2012.04192.x. [PMC free article] [PubMed] [CrossRef] [Google Scholar]
7. Hely MA, Morris JG, Reid WG, Trafficante R. Sydney Multicenter Study of Parkinson's disease: non-L-dopa-responsie problems dominate at 15 years. Mo Disord. 2005;20:190-199. doi: 10.1002/mds.20324. [PubMed] [CrossRef] [Google Scholar]

8. Lopez IC, Ruiz PJ, Del Pozo S, Bernardos S. Motor complications in Parkinson's disease: ten year follow-up study. Mo Disord. 2010;25:2735-2739. doi: 10.1002/mds.23219. [PubMed] [CrossRef] [Google Scholar]

9. Maillet A, Pollak P, Debû B. Imaging gait disorders in parkinsonism: a reiew. J Neurol Neurosurg Psychiatry. 2012;83:986-993. doi: 10.1136/jnnp-2012-302461. [PubMed] [CrossRef] [Google Scholar]

10. Dobson, A. J. \& Barnett, A. An introduction to generalized linear models. (CRC press, 2008).

11. Breiman L. Random forests. Machine learning. 2001;45:5-32. doi 10.1023/A:1010933404324. [CrossRef] [Google Scholar]

12. Rätsch G, Onoda T, Müller K-R. Soft margins for AdaBoost. Machine learning. 2001;42:287-320. doi: 10.1023/A:1007618119488. [CrossRef] [Google Scholar]

13. Chen, T. \& Guestrin, C. In Proceedings of the 22 nd acm sigkdd international conference on knowledge discoery and data mining. 785-794 (ACM).

14. Hearst MA, Dumais ST, Osuna E, Platt J, Scholkopf B. Support ector machines. IEEE Intelligent Systems and their applications. 1998;13:18-28. doi: 10.1109/5254.708428. [CrossRef] [Google Scholar]

15. Anagnostou T, Remzi M, Lykourinas M, Djaan B. Artificial neural networks for decision-making in urologic oncology. European urology. 2003;43:596-603. doi: 10.1016/S0302-2838(03)00133-7. [PubMed] [CrossRef] [Google Scholar]

16. An der Laan, M. J., Polley, E. C. \& Hubbard, A. E. Super learner. Statistical applications in genetics and molecular biology6 (2007). [PubMed]

17. Abós A, et al. Discriminating cognitie status in Parkinson's disease through functional connectomics and machine learning. Scientific reports. 2017;7:45347. doi: 10.1038/srep45347. [PMC free article] [PubMed] [CrossRef] [Google Scholar]

18. Dinesh, A. \& He, J. In 2017 IEEE MIT Undergraduate Research Technology Conference (URTC). 1-4.

19. Peng B, et al. A multileel-ROI-features-based machine learning method for detection of morphometric biomarkers in Parkinson's disease. Neuroscience Letters. 2017;651:88-94. doi 10.1016/j.neulet.2017.04.034. [PubMed] [CrossRef] [Google Scholar]

20. Lei H, et al. Joint detection and clinical score prediction in Parkinson's disease ia multi-modal sparse learning. Expert Systems with Applications. 2017;80:284-296. doi: 10.1016/j.eswa.2017.03.038. [CrossRef] [Google Scholar] 